Article

\title{
Development and Characterization of Inkjet Printed Edible Films for Buccal Delivery of B-Complex Vitamins
}

\author{
Georgios Eleftheriadis ${ }^{1, *(D)}$, Paraskevi Kyriaki Monou 1ㄹ, Eleftherios Andriotis ${ }^{1}$, \\ Elisavet Mitsouli ${ }^{1}$, Nikoleta Moutafidou ${ }^{2}$, Catherine Markopoulou ${ }^{2}$, \\ Nikolaos Bouropoulos $3,4, * \mathbb{D}$ and Dimitrios Fatouros ${ }^{1}$ \\ 1 Laboratory of Pharmaceutical Technology, School of Pharmacy, Aristotle University of Thessaloniki, \\ 54124 Thessaloniki, Greece; paraskemd@pharm.auth.gr (P.K.M.); andrioti@pharm.auth.gr (E.A.); \\ mitsoulielsa@gmail.com (E.M.); dfatouro@pharm.auth.gr (D.F.) \\ 2 Laboratory of Pharmaceutical Analysis, School of Pharmacy, Aristotle University of Thessaloniki, \\ 54124 Thessaloniki, Greece; nikoletam@pharm.auth.gr (N.M.); amarkopo@pharm.auth.gr (C.M.) \\ 3 Department of Materials Science, University of Patras, Rio, 26504 Patras, Greece \\ 4 Foundation for Research and Technology Hellas, Institute of Chemical Engineering and High Temperature, \\ Chemical Processes, 26504 Patras, Greece \\ * Correspondence: gkelefth@pharm.auth.gr (G.E.); nbouro@upatras.gr (N.B.); Tel.: +30-231-099-7653 (G.E.); \\ $+30-261-099-7164$ (N.B.)
}

Received: 28 June 2020; Accepted: 18 August 2020; Published: 20 August 2020

\begin{abstract}
Buccal films containing two vitamins, i.e., thiamine hydrochloride ( $\mathrm{THCl})$ and nicotinic acid (NA), were fabricated via two-dimensional (2D) inkjet printing. For the preparation of buccal films, solubility studies and rheological evaluations were conducted in distilled water and propylene-glycol (PG) as main solvent and viscosity/surface tension modifier, respectively. The increased solubility in the solvents' mixture indicated that manufacturing of several doses of the $\mathrm{THCl}$ and $\mathrm{NA}$ is achievable. Various doses were deposited onto sugar-sheet substrates, by increasing the number of printing passes. The physiochemical characterization (SEM, DSC, FTIR) revealed that inkjet printing does not affect the solid state of the matrix. Water uptake studies were conducted, to compare the different vitamin-loaded formulations. The in vitro release studies indicated the burst release of both vitamins within $10 \mathrm{~min}$, a preferable feature for buccal administration. The in vitro permeation studies indicated that higher concentrations of the vitamins onto the sugar sheet improved the in vitro permeation performance of printed formulations.
\end{abstract}

Keywords: buccal delivery; inkjet printing; B-complex vitamins; thiamine hydrochloride; nicotinic acid; release

\section{Introduction}

In the last decade, printing technologies have gained popularity in the pharmaceutical field. Inkjet printing, in particular, is a non-contact method for alternative manufacturing of orally delivered formulations [1]. Drop-on-demand thermal inkjet printing provides a number of advantages in pharmaceutical technology. It facilitates the deposition of small amounts of liquids onto edible substrates, while the formulation is based on predesigned digital patterns [2]. The procedure is based on the generation of thermal pulses and the subsequent formation of a vapor bubble which expands and forces the liquid ink through the nozzle of the printer's cartridge. Thus, a liquid droplet is formed directly and sprayed onto the substrate [3]. 
Personalized dosing is a new aspect in the pharmaceutical field and printing technologies are promising formulation approaches toward this direction, as they can produce various doses of one's medicine in a tailored way [4]. Age, gender, and other genomic features vary among individuals, and as a result various doses of a medicine should be available for each patient in a fast and safe way [5]. Furthermore, the 2D inkjet printing technology provides the potential to advance the loading of poorly soluble drugs in a medicinal formulation, following the exploitation of suitable solvents in the development of inks [6]. The inkjet printing technique has been coupled with other formulation approaches, to fabricate hybrid drug delivery systems [7-9].

In order to achieve the optimal printability of the ink, the rheology of the liquid is the main factor that should be investigated. Specifically, viscosity and surface tension are critical parameters, as viscous liquids advance the formation of clogs and low-viscosity liquids would flow freely through the nozzle of the cartridge $[10,11]$. The use of viscosity and surface tension modifiers is imperative to produce a printable ink. Surfactants and polyhydric alcohols have been reported to effectively modify the rheological properties of the ink and to improve the solubility of several drugs.

Prednisolone and folic acid are representative active pharmaceutical compounds (APIs) that exhibit low solubility in the most common solvents; however these compounds were successfully formulated into oral dosage forms by inkjet printing [12,13]. Loperamide and caffeine were used as model drugs in order to investigate the preparation of flexible doses by inkjet printing [14], whereas the utilization of different substrates for loading rasagiline mesylate has been reported [15] Paracetamol, theophylline and caffeine were printed in porous substrates, presenting an alternative approach to control the deposition and the crystallization of the drugs [16]. Levothyroxine has been formulated by inkjet printing in order to develop flexible pediatric dosage forms [17]. Combining inkjet printing with the Quick Response $(\mathrm{QR})$ technology also seems very promising, as practical information is encoded in drug loaded QR patterns (expiration date, route of administration, batch number, and manufacturer ID) and smart dosage forms are being formed for every individual $[18,19]$.

The buccal delivery of APIs is an alternative, non-invasive route of administration that provides beneficial health effects. The buccal mucosa is a highly vascularized administration site, providing the high permeability for many APIs and the avoidance of the first pass effect [20]. Buccal formulations are recommended for pediatric dosage forms as they are patient-friendly and adjustable to the different physiological and pharmacokinetic profiles of infants, children and adolescents [21]. Clobetasol, omeprazole, and hydrocortisone are representative model drugs which have been formulated for buccal delivery [22-24]. The applicability of various printing technologies for patient-centric buccal formulations has been demonstrated by previous reports, in terms of (i) incorporating personalized doses or thermolabile drugs, and (ii) fabricating multi-layered buccal films $[4,8,9,25]$.

B-complex vitamins are vital compounds for the proper functioning of the nervous system, the conversion of glucose into energy, and the metabolism of fats and proteins [26]. Buccal formulations of water soluble vitamins have been reported as patient-friendly dosage forms $[27,28]$. Factors like the saliva flow, chewing, swallowing, and speech may cause shearing in the oral cavity and obstruct the adhesion to the buccal mucosa, thus raising bioavailability issues; to address this, the burst release behavior of the formulations is able to simultaneously promote the diffusion of the API from the carrier and the rapid absorption by the mucus [29].

Thiamine hydrochloride (vitamin $\mathrm{B} 1, \mathrm{THCl}$ ) is a hydrophilic vitamin, insoluble in the most common organic solvents, but soluble in polar solvents. It is vital for the maintenance of neuritis and polyneuritis. This vitamin is essential for the biosynthesis of gamma aminobutyric acid (GABA) and acetylcholine, the main neurotransmitter of the autonomic nervous system and also acts as a co-enzyme in the metabolism of fats, proteins and carbohydrates [30]. B1 deficiency may cause serious neurological and respiratory problems, dysfunction of the cardiovascular system, ophthalmoplegia, and nystagmus. Humans are unable to synthesize thiamine, and the recommended daily dose of B1 is $1.2 \mathrm{mg}$ per day for adults and $0.2 \mathrm{mg}$ per day for infants [31,32]. Grain and cereal-grain food products are the main source for B-complex vitamins, and it is claimed that the consumption of such products 
provides a positive effect in a variety of health-related conditions, e.g., diabetes, cardiovascular diseases, cancer of the colon, and lowering of blood cholesterol levels [33].

Nicotinic acid (vitamin B3, NA) is the precursor of nicotinamide adenine dinucleotide (NAD) and nicotinamide adenine dinucleotide phosphate (NADP), coenzymes that are involved in cellular redox reactions, along with nicotinamide. Moreover, NA seems to play a key role in the methylation of different substrates, including DNA, epinephrine and norepinephrine [34]. These findings suggest that NA is of highly importance for the human metabolic regulation and cell growth [35]. The NA vitamin is also involved in the metabolism of lipids, reducing the plasma levels of triglyceride and very low-density lipoprotein (VLDL), and resulting in raised levels of high-density lipoprotein (HDL). On top of that, B3 can cause blood vessel dilation, therefore it has a positive effect in various treatments such as hyperlipidemia, headache, vascular migraine, and cerebral arterial thrombosis. Some studies suggest that in can also manifest a neuroprotective behavior in stroke [36]. The recommended daily dose of NA is $15 \mathrm{mg}$ per day for adults and it is synthesized from tryptophan, an amino acid inside the human body [37].

Both NA and $\mathrm{THCl}$ are B-group vitamins, essential for the nervous system and of high nutritional value. The buccal administration of these vitamins may have a very positive effect in cases of deficiency or poor nutrition. It has been reported that the combined NA and $\mathrm{THCl}$ administration provides anti-inflammatory properties and can reduce edema [38]. The aim of this study is to produce 2D-printed buccal films for the administration of these vitamins. Edible sheets were used as substrates for the deposition of the vitamin-loaded liquid ink and the formulation of the buccal films. These edible sugar sheets consist mainly of sugar monosaccharides and a polysaccharide, i.e., maltodextrin. These hydrophilic macromolecules contain hydrogen bond forming groups, thus favoring the adhesion to the buccal mucosa [39-41]. Propylene glycol was incorporated in the liquid ink as viscosity modifier, and has been reported to enhance the permeation and adhesion properties of buccal films [8,9,42]. Solubility studies, surface tension, and viscosity measurements were performed to determine the optimal liquid ink. Films with different doses can be produced by increasing the number of sequential passes from the printer, thus vitamin loading, and water uptake measurements are presented. Physiochemical characterization of the films, as well as in vitro release and in vitro permeation studies were also executed, to assess the developed formulations.

\section{Results}

\subsection{Solubility Studies}

The solubility studies for Nicotinic acid are presented in Table 1. The results indicated that NA is more soluble in water, as expected. The saturation solubility in water and in PG was $14.3 \mathrm{mg} / \mathrm{mL}$ and $8.4 \mathrm{mg} / \mathrm{mL}$ respectively. Regarding $\mathrm{THCl}$, the solubility testing in water and in PG was terminated at a content of $198 \mathrm{mg} / \mathrm{mL}$ and $100 \mathrm{mg} / \mathrm{mL}$, respectively, due to the observed increase in viscosity of the solutions, although, the solvents were capable of dissolving further amounts of the vitamin.

Table 1. Solubility studies for nicotinic acid (NA).

\begin{tabular}{cc}
\hline Solvent & Solubility $(\mathrm{mg} / \mathrm{mL})$ \\
\hline Distilled Water & 14.3 \\
Propylene glycol & 8.4 \\
\hline
\end{tabular}

\subsection{Viscosity and Surface Tension Measurements}

Table 2 shows the viscosity values of 50:50, 60:40, 70:30, and 80:20 (\% v/v) of $\mathrm{H}_{2} \mathrm{O}: \mathrm{PG}$ binary mixtures. Vitamin-free binary mixtures were initially tested, whereas the addition of vitamins into the ink increased the viscosity. By increasing the concentration of both vitamins with a steady ratio between them, produced a very viscous ink solution, which was incapable of jetting through the ink cartridge. Finally, a vitamin content of $200 \mathrm{mg} / \mathrm{mL}$ and $12 \mathrm{mg} / \mathrm{mL}$ for THCL and NA, respectively, in a 
$\mathrm{H}_{2} \mathrm{O}: \mathrm{PG}$ ratio of $60: 40(v / v)$ was selected as the optimal composition, following the evaluation of the 2D printing process.

Table 2. Viscosity and surface tension measurements of the liquid inks.

\begin{tabular}{|c|c|c|c|c|c|}
\hline $\begin{array}{c}\mathrm{H}_{2} \mathrm{O} \text { :PG Ratio } \\
(\% v / v)\end{array}$ & $\mathrm{THCl}(\mathrm{mg} / \mathrm{mL})$ & NA (mg/mL) & $\begin{array}{c}\text { Kinematic Viscosity } \\
\left(\mathrm{mm}^{2} / \mathrm{s}\right)\end{array}$ & $\begin{array}{l}\text { Dynamic Viscosity } \\
(\mathrm{mPa} \times \mathrm{s})\end{array}$ & $\begin{array}{l}\text { Surface Tension } \\
\quad(\mathrm{mN} / \mathrm{m})\end{array}$ \\
\hline $80: 20$ & - & - & $2.105 \pm 0.02$ & $2.157 \pm 0.03$ & - \\
\hline 70:30 & - & - & $3.087 \pm 0.06$ & $3.173 \pm 0.02$ & - \\
\hline 60:40 & - & - & $4.294 \pm 0.04$ & $4.476 \pm 0.08$ & $26.8 \pm 0.05$ \\
\hline 60:40 & 200.0 & 12.0 & $5.356 \pm 0.03$ & $5.525 \pm 0.01$ & $28.4 \pm 0.03$ \\
\hline $60: 40$ & 230.0 & 13.8 & $12.316 \pm 0.07$ & $12.598 \pm 0.03$ & - \\
\hline
\end{tabular}

\subsection{Vitamin Loading and Water Uptake of the Developed Films}

The amount of both vitamins in the formulated films was effectively increased, depending on the number of printing passes. Multiple passes through the printer produced three different formulations, with various doses of $\mathrm{THCl}$ and NA. The films were isolated manually from the substrate using a surgical blade; hence the content of vitamins is presented as mass of vitamin per mass of film. In detail, $\mathrm{THCl}$ content was $3.34 \pm 0.03,7.55 \pm 0.09$, and $9.39 \pm 0.02 \mu \mathrm{g} / \mathrm{mg}$ film and NA content was $0.17 \pm 0.001$, $0.39 \pm 0.004$, and $0.57 \pm 0.001 \mu \mathrm{g} / \mathrm{mg}$ film for 1-, 5-, and 9-times printed formulations, respectively. The water uptake results are presented in Figure 1. The water absorption capacity for all formulations was in the range $13-17 \%$ at $10 \mathrm{~s}$ and $19-23 \%$ at $20 \mathrm{~s}$. Further immersion of the films in the medium promoted the extended deformation of structural integrity.

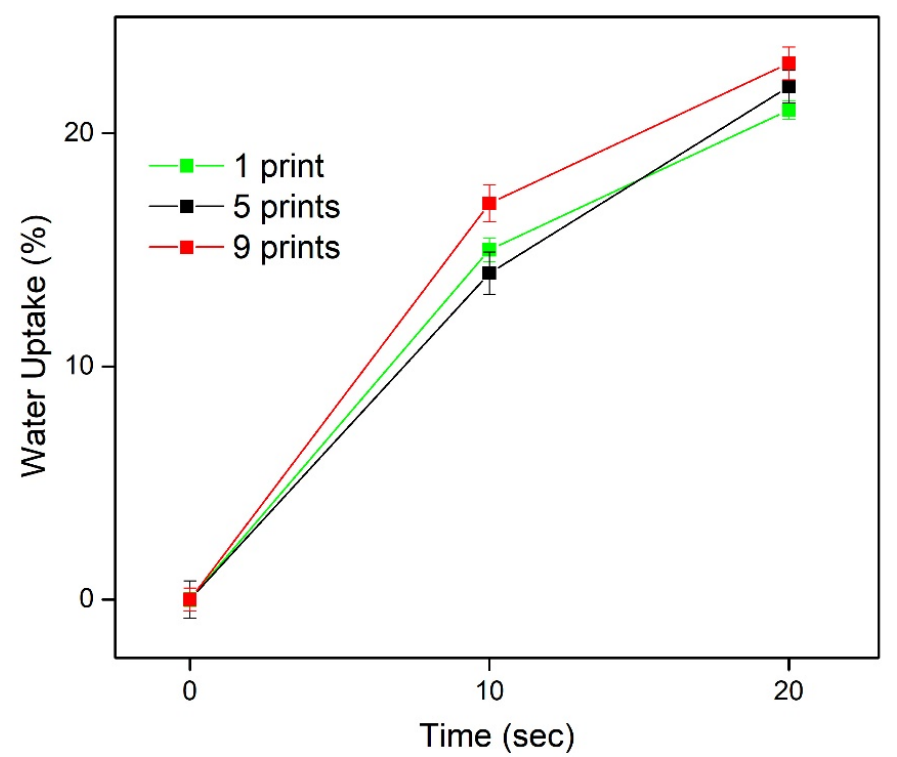

Figure 1. Water uptake of 1,5, and 9 times printed films.

\subsection{Thickness and Moisture Content}

The thickness of the plain substrate was $0.558 \pm 0.001 \mathrm{~mm}$, while the thickness of the 1-, 5-, and 9-printed specimens was $0.557 \pm 0.005,0.558 \pm 0.007$, and $0.558 \pm 0.005 \mathrm{~mm}$, respectively, indicating the absence of post-printing alterations on the geometric characteristics of the films $(p>0.05)$. The moisture content of the printed formulations and the plain sugar sheet was calculated by weighing the films before and after drying at $105^{\circ} \mathrm{C}$. The elimination of additional decomposition phenomena at this temperature range was based on the thermo-gravimetric analysis (TGA) evidence (Figure 2). The TGA thermograms revealed that the percentage of water is approximately $7 \%$ for all samples, indicated by mass losses at the temperature range of $50-150{ }^{\circ} \mathrm{C}$, whereas thermal decomposition phenomena of $\mathrm{THCl}$ and NA appear to initiate at $210^{\circ} \mathrm{C}$ and $160^{\circ} \mathrm{C}$, respectively. The moisture content calculated 
with the drying method was $8.21 \pm 0.05 \%, 8.23 \pm 0.07 \%, 8.25 \pm 0.09 \%$, and $8.29 \pm 0.08 \%$ for sugar sheet, $1-, 5-$, and 9-printed films, respectively $(p>0.05)$.

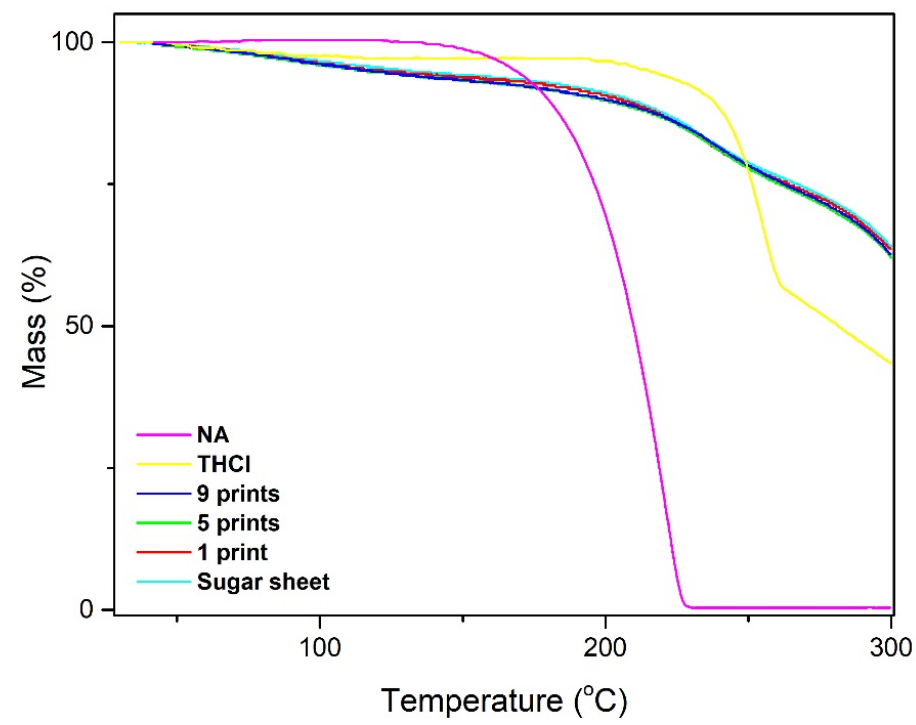

Figure 2. Thermo-gravimetric analysis of raw materials and printed formulations for the calculation of the moisture content.

\subsection{Physiochemical Characterization}

The SEM micrographs are presented in Figure 3. Upper and side views of the formulations revealed the rough surface and the presence of a pore network in the plain substrate matrix. Similar characteristics were apparent in 9-times printed films; however, the surface appears to be smoother and the substrate grains are merged in contrast to the plain substrate.
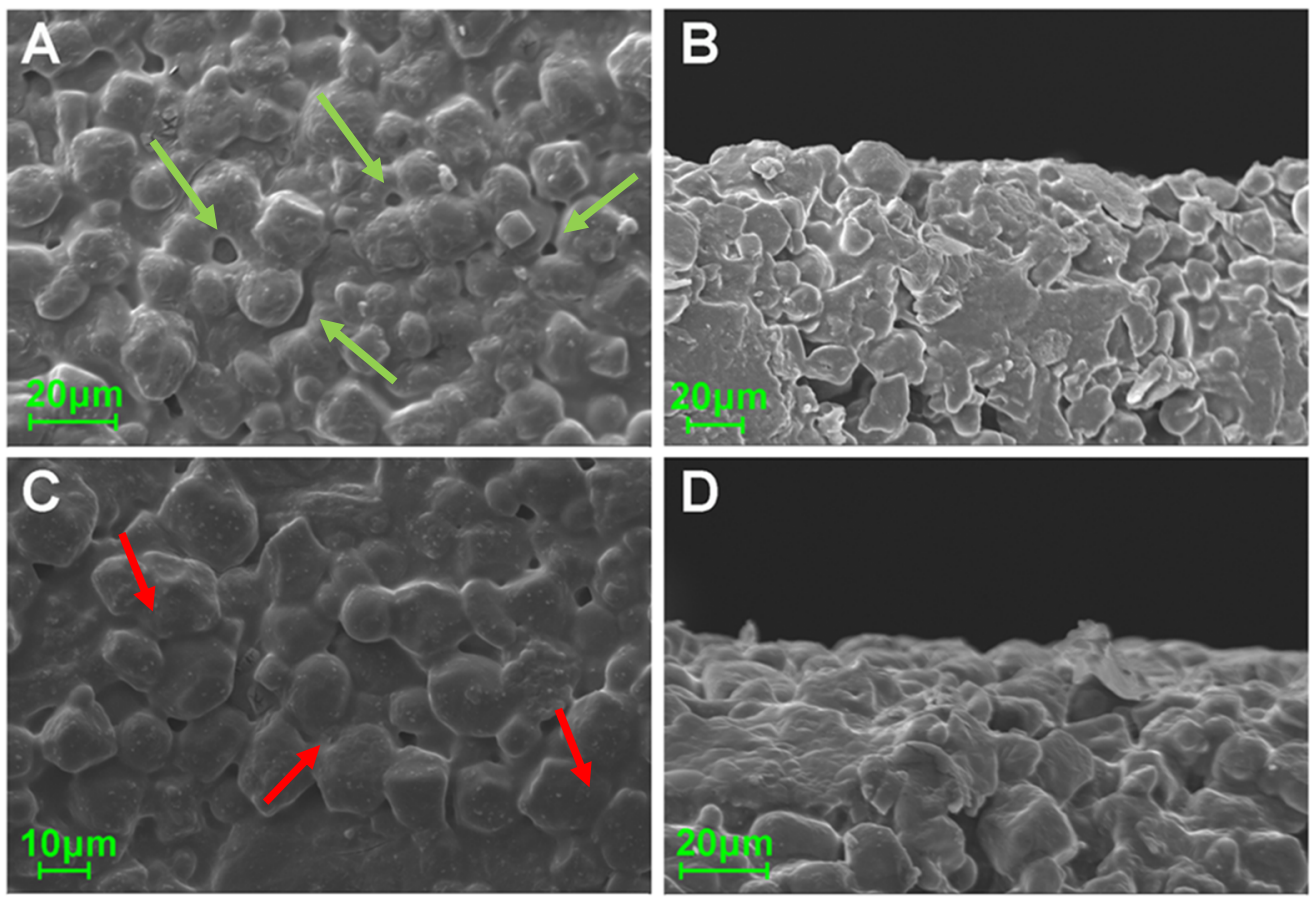

Figure 3. SEM micrographs of the upper and side surfaces of plain (A,B) and nine-pass (9)-printed (C,D) sugar sheets. The pores are marked with green arrows while the merged grains are marked with red arrows. 
The physiochemical properties of the films and the raw materials are shown in Figure 4. The DSC thermograms of $\mathrm{THCl}$ and NA presented a sharp endothermic peak at $260^{\circ} \mathrm{C}$ and $240{ }^{\circ} \mathrm{C}$, respectively. No such endotherms were recorded in the printed formulations. The formulations and the plain sugar sheet presented two broad endothermic peaks in the $70-150{ }^{\circ} \mathrm{C}$ and $190-250{ }^{\circ} \mathrm{C}$ range. Figure $4 \mathrm{~b}$ illustrates the FTIR spectra of plain materials and printed formulations. In the spectrum of $\mathrm{THCl}$, characteristic peaks at 1650,1600,1347, and $1438 \mathrm{~cm}^{-1}$ are apparent, whereas in the NA spectrum vibrations occurred in the range of $1770-1580 \mathrm{~cm}^{-1}$ and $1500-1300 \mathrm{~cm}^{-1}$. The plain sugar sheet, as well as the 1-, 5-, and 9-times printed films presented distinct vibrations in the area 3000-3500 $\mathrm{cm}^{-1}$ and $1200-700 \mathrm{~cm}^{-1}$. The characteristic vibrations of both vitamins were not detected in the developed formulations.

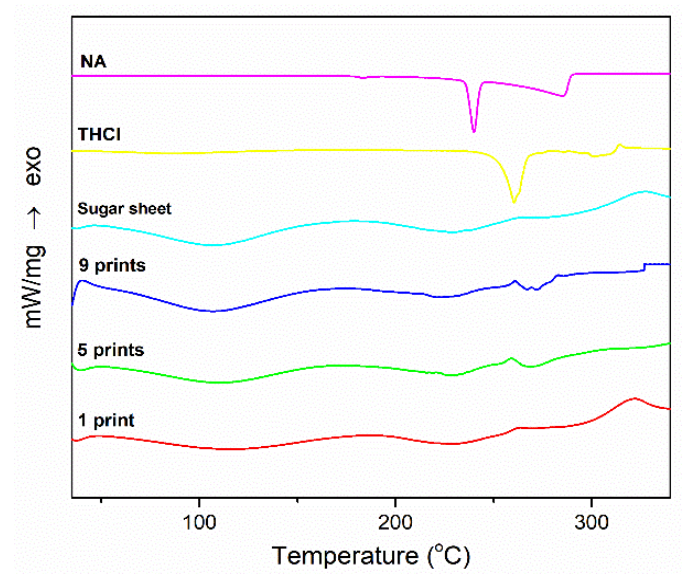

(a)

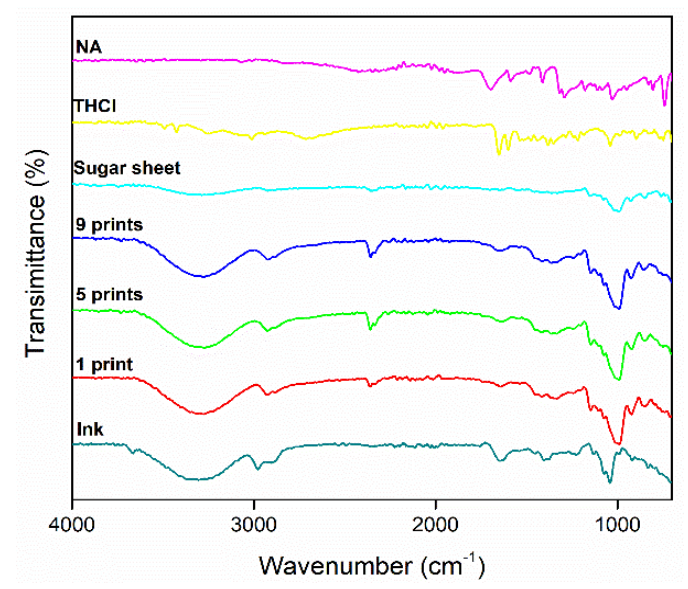

(b)

Figure 4. (a) DSC thermograms and (b) FTIR spectra of the samples.

\subsection{FTIR Data Analysis}

\subsubsection{Two-Dimensional Fourier Transformation Infrared Correlation Spectroscopy (2D-COS-FTIR)}

2D-COS-FTIR was applied to monitor the dynamic spectral changes of the specimens during subsequent passes through the printer. The auto-peaks plot (Figure 5) was generated, based on the synchronous 2D-COS-FTIR analysis. The correlated data show that there are dynamic changes of the spectra, occurring around 1061 and $978 \mathrm{~cm}^{-1}$. These bands are attributed to the sugar sheet, indicating that the printing process alters the surface of the substrate. Considering the absence of further changes, it was suggested that the surface of the film is wetted by the ink as of the first printing pass, without any accumulation of ink, and the ink was instantly absorbed into the bulk of the substrate (film).

\subsubsection{Moving-Window 2D (MW2D) Correlation Spectroscopy}

MW2D analysis was applied and the contour map (Figure 6) was generated, to visualize the peak dynamic changes across the perturbation axis (sequential inkjet passes). The bands around $1061 \mathrm{~cm}^{-1}$ and $978 \mathrm{~cm}^{-1}$ exhibit changes over the investigated range of printing passes. Variations regarding the $\mathrm{OH}$ bonds of the sugar sheet were not detected, indicating the absence of ink accumulation onto the surface of the substrate. 


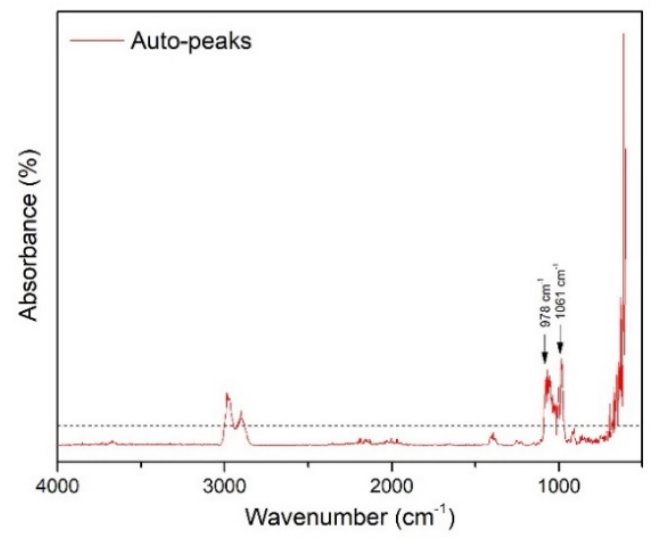

Figure 5. Two-dimensional Fourier transformation infrared correlation spectroscopy (2D-COS-FTIR) technique generated the auto-peaks plot.

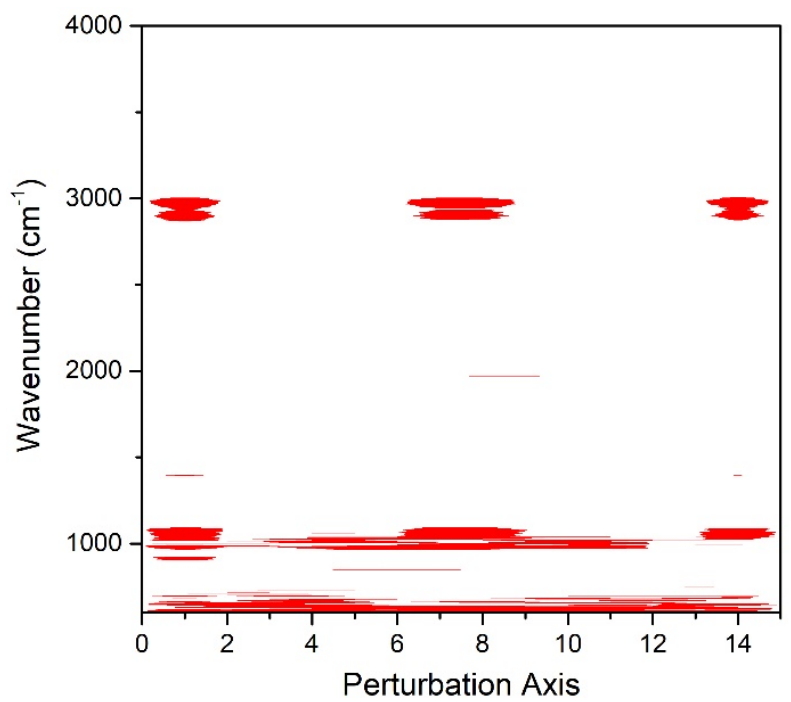

Figure 6. MW2D contour map for the visualization of the dynamic spectra changes.

\subsection{In Vitro Release}

The release of the vitamins in simulated saliva (SS) was monitored for $1 \mathrm{~h}$. Figure 7 demonstrates the release profiles of the two compounds. All formulations released most of the loaded content within $10 \mathrm{~min}$. In detail, $85 \%, 98 \%$, and $100 \%$ of $\mathrm{THCl}$ and $78 \%, 85 \%$, and $100 \%$ of NA was released at 7.5 min from 1, 5, and 9-times printed films, respectively. The obtained parameters from the curve fitting process are presented in Table 3. The data revealed that the profiles of all formulation for both THCL and NA release were optimally fitted to the first order kinetic model, with $\mathrm{R}^{2}$ values in the range 0.975-0.996.

Table 3. Kinetic models fitting parameters.

\begin{tabular}{ccccccc}
\hline Formulation & Vitamin & \multicolumn{2}{c}{ First Order } & \multicolumn{3}{c}{ Korsmeyer-Peppas } \\
\hline \multirow{2}{*}{ 1-print } & & $\mathrm{k}$ & $\mathrm{R}^{2}$ & $\mathrm{k}$ & $\mathrm{n}$ & $\mathrm{R}^{2}$ \\
& $\mathrm{THCl}$ & 0.29 & 0.986 & 53.04 & 0.20 & 0.929 \\
\multirow{2}{*}{ 5-prints } & $\mathrm{NA}$ & 0.21 & 0.975 & 43.14 & 0.27 & 0.898 \\
& $\mathrm{THCl}$ & 0.34 & 0.990 & 61.66 & 0.16 & 0.930 \\
9-prints & $\mathrm{NA}$ & 0.28 & 0.988 & 55.45 & 0.19 & 0.943 \\
& $\mathrm{THCl}$ & 0.64 & 0.996 & 83.32 & 0.07 & 0.978 \\
& $\mathrm{NA}$ & 0.52 & 0.990 & 77.35 & 0.09 & 0.950 \\
\hline
\end{tabular}




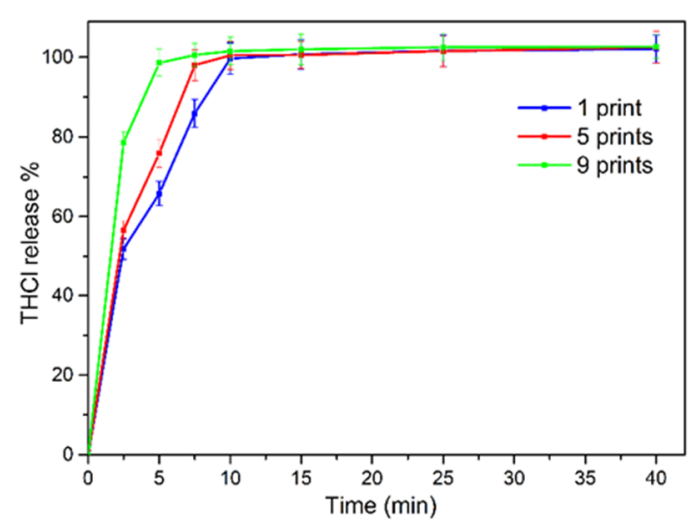

(a)

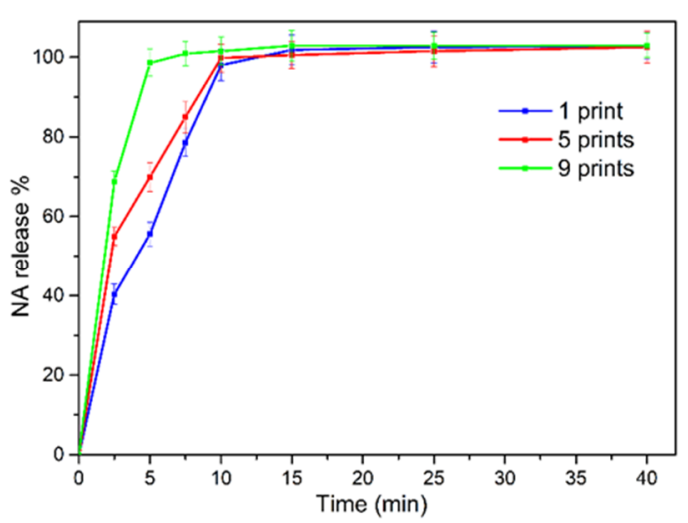

(b)

Figure 7. (a) Release profile of thiamine hydrochloride ( $\mathrm{THCl}$ ) and (b) NA.

\subsection{In Vitro Permeation}

Figure 8 illustrates the in vitro permeation profiles of the two vitamins, whereas Tables 4 and 5 correspond to the permeation parameters of the study. It was evidenced that the increasing amount of vitamins content resulted in higher cumulative amounts that permeated across the cellulosic membrane. Accordingly, the steady-state flux and the apparent permeability coefficient were altered, in association with the number of printing passes. For $\mathrm{THCl}$, the $\mathrm{J}_{\mathrm{ss}}$ and $\mathrm{P}_{\mathrm{app}}$ values were increased for 5 and 9-times printed films. Similarly, NA exhibited increased $\mathrm{J}_{\mathrm{ss}}$ and $\mathrm{P}_{\mathrm{app}}$ values of the 5- and 9- printed films, compared to the 1-printed specimen.

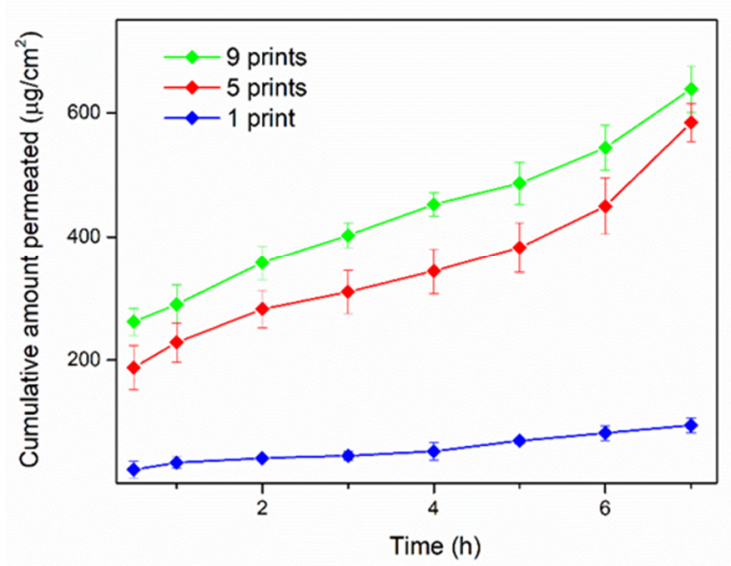

(a)

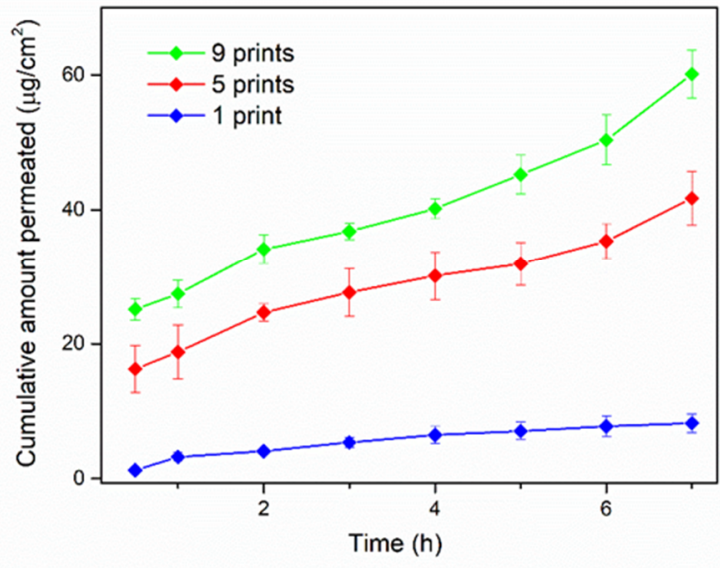

(b)

Figure 8. Cumulative transport of (a) $\mathrm{THCl}$ and (b) NA across the cellulose membrane.

Table 4. Permeation parameters for THCl.

\begin{tabular}{|c|c|c|}
\hline Printed Layers & $\mathrm{J}_{\mathrm{ss}}\left(\mu \mathrm{g} \times \mathrm{cm}^{-2} \times \mathrm{h}^{-1}\right)$ & $P_{\text {app }} \cdot 10^{-4}\left(\mathrm{~cm} \times h^{-1}\right)$ \\
\hline 1 & $0.206 \pm 0.06$ & $1.322 \pm 0.39$ \\
\hline 5 & $1.684 \pm 0.32$ & $4.700 \pm 0.40$ \\
\hline 9 & $1.710 \pm 0.41$ & $6.690 \pm 1.80$ \\
\hline
\end{tabular}

Table 5. Permeation parameters for NA.

\begin{tabular}{|c|c|c|}
\hline Printed Layers & $\mathrm{J}_{\mathrm{ss}}\left(\mu \mathrm{g} \times \mathrm{cm}^{-2} \times \mathrm{h}^{-1}\right)$ & $P_{\mathrm{app}} \cdot 10^{-4}\left(\mathrm{~cm} \times \mathrm{h}^{-1}\right)$ \\
\hline 1 & $0.009 \pm 0.001$ & $1.204 \pm 0.150$ \\
\hline 5 & $0.082 \pm 0.018$ & $4.085 \pm 0.910$ \\
\hline 9 & $0.142 \pm 0.050$ & $11.188 \pm 1.120$ \\
\hline
\end{tabular}




\section{Discussion}

$\mathrm{THCl}$ and NA are vitamins with low bioavailability when administered per os. $\mathrm{THCl}$ is absorbed in the jejunum and ileum by both passive and active uptake and reaches the systemic circulation after passing through the liver. Excess amounts of $\mathrm{THCl}$ are excreted through the renal clearance and the bioavailability is between $3.7 \%$ and $5.3 \%$ [43,44]. NA has a relative bioavailability of up to $25 \%$, whereas $15-30 \%$ of the absorbed vitamin bounds to plasma proteins. NA has an extensive hepatic metabolism, which is also associated with the hepatic toxicity caused by higher doses of NA [45-47]. Buccal delivery of APIs has the main advantage of bypassing the first pass effect, including the avoidance of presystemic elimination within the GI tract. Thus, higher plasma concentrations of the drugs are achievable and the drug content within the buccal formulations is considerably lower, potentially reducing toxicity and other side effects [48]. To this context, we proposed a proof-of-concept approach for the buccal administration of these vitamins, whereas further optimization of these drug delivery systems is required.

Viscosity and surface tension are important factors to be considered in the development of liquid inks, intended for inkjet printing. Certain limits of the values of these parameters have been reported, regarding the available equipment; $1-30 \mathrm{mPa} \times \mathrm{sec}$ for viscosity and $25-50 \mathrm{mN} / \mathrm{m}$ for surface tension $[11,14]$. Considering that the addition of vitamins in the ink will increase the viscosity, the composition of the plain $\mathrm{H}_{2} \mathrm{O}: \mathrm{PG}$ binary mixture that was selected for further studies presented the optimal printing performance. In the case of $60: 40(\% v / v)$ ratio, a dynamic viscosity of $4.476 \mathrm{mPa} \times \mathrm{s}$ was calculated and an increasing amount of the two substances (under a steady ratio) was added in the mixture to produce a favorable ink solution. The optimal ink was selected with regard to the inkjet printing performance, i.e., the homogeneous distribution of the ink onto the edible substrate. Higher concentrations of the vitamins resulted in high-viscosity mixtures, unable to be jetted from the printer cartridge. Subsequently, the optimal ink was infused in the black ink cartridge. The buccal films were produced with sequential deposition of the vitamins onto the edible sugar sheets. By increasing the number of passes of the sugar sheet through the printer, various doses of the vitamins were produced. However, the 5- and 9-printed films presented lower vitamin dosing than expected, when compared to the 1-printed film. The disproportionate increase in dosing of inkjet-printed formulations, in relation to the number of printing passes, has been previously reported and associated with the shear forces that develop during the feeding process of the printer $[49,50]$. The conveyance of the edible sheets to the printing zone occurs upon traction of the substrate by the drive rollers of the device. Thus, at multiple printing passes, the generated shear forces often result in spreading of the ink beyond the printing boundaries of the predesigned patterns.

The morphological assessment revealed the rough surface of the sugar sheet and a smoothing of the surface of the ink-loaded film, due to partial solubilization of the superficial molecules. However, the printing process did not affect the overall geometry of the fabricated films, as revealed by the measured thickness values of the specimens. The commercial sugar sheet used in the present study is flexible and is intended to be used as substrate for printing edible substances. It was assumed that the amount of deposited ink onto the films was not efficient for altering the mechanical properties of the formulations. Although an increasing number of sequential printing passes was performed, the determined moisture content was similar for all specimens. This was indicative of the tightly bound water molecules in the substrate's matrix, whereas a major amount of water molecules from the ink was instantly evaporated upon formation of liquid droplets at the printer's orifice and the dispersion of droplets onto the substrates [8]. Moreover, the TGA data assured that the observed mass alterations upon drying were exclusively attributed to water evaporation, as thermal decomposition phenomena of the incorporated materials were observed at higher temperatures, compared to the drying conditions $\left(105^{\circ} \mathrm{C}\right)$. The DSC thermograms demonstrated sharp endothermic peaks at $260{ }^{\circ} \mathrm{C}$ and $240{ }^{\circ} \mathrm{C}$ for $\mathrm{THCl}$ and NA respectively, indicating the melting points of the vitamins [30,51]. These endotherms were not detected in the printed formulations, due to the amorphous state of the vitamins in the films or to the content of vitamins being below the detection limit of the instrument. At 5- and 9-prints, 
an endothermic peak around $260^{\circ} \mathrm{C}$ was present as a sequence of an exothermic peak. These peaks indicate the recrystallization of $\mathrm{THCl}$ upon heating, followed by the melting of the substance [52]. Two broad endotherm peaks were detected in the temperature range of $70-150{ }^{\circ} \mathrm{C}$ and $190-250{ }^{\circ} \mathrm{C}$ for the plain sugar sheet and the formulations. These peaks are attributed to the evaporation of water and to the endothermic patterns of maltodextrin and sugar monosaccharides [50]. In the FTIR spectrum of $\mathrm{THCl}$, characteristic peaks at $1650 \mathrm{~cm}^{-1}$ and $1600 \mathrm{~cm}^{-1}$ corresponded to the stretching bonds of $\mathrm{C}=$ $\mathrm{N}$ and aromatic $\mathrm{C}=\mathrm{C}$ respectively [53] and peaks at $1347 \mathrm{~cm}^{-1}$ and $1438 \mathrm{~cm}^{-1}$ corresponded to the stretching modes of $\mathrm{CH}$ group of the pyrimidine ring [54]. Regarding NA, the stretching vibrations of $\mathrm{C}-\mathrm{C}$ and $\mathrm{COOH}$ occurred in the range $1770-1580 \mathrm{~cm}^{-1}$, and the vibrations at $1500-1300 \mathrm{~cm}^{-1}$ were associated with the C-C and H-O bonds. Distinct vibrations of the sugar sheet in the area 3000-3500 $\mathrm{cm}^{-1}$ and $1200-700 \mathrm{~cm}^{-1}$ were present in all formulations. These vibrations were associated with the presence of maltodextrin, which is incorporated in the composition of the sugar sheet [55]. The absence or lower transmittance of the characteristic vibrations in the developed formulations including the ink solution, suggests that the vitamins content was either below the detection limit of the device or the vitamins were molecularly dissolved in the substrate matrix $[50,56]$.

The 2D-COS-FTIR method allowed the monitoring of the surface changes at sequential inkjet printing. The correlated data indicate that there are no intensity changes of the bands that are associated with the surface matrix at $3200-3500 \mathrm{~cm}^{-1}$. These bands are attributed to the $\mathrm{OH}$ bonds of the sugar sheet. Since these peaks are present in the FTIR spectra of the individual films, but their intensity is not changed, it is considered that the ink is not accumulated on the surface of the films, but it is absorbed into the substrate matrix. The dynamic changes that occurred around $1061 \mathrm{~cm}^{-1}$ and at $978 \mathrm{~cm}^{-1}$ were attributed to the increase of the concentration of glycosidic bonds of maltodextrin [57]. The MW2D contour plot showed changes that occur across the investigated number of sequential prints, suggesting alterations on the surface of the sugar sheet that increased the contact area between the ATR crystal and the specimen. A possible mechanism that explains this observation is the partial surface erosion due to substrate dissolution phenomena. The ink acts as a solvent for the substrate leading the sugar to dissolve and recrystallize during the sequential cycles of printing. This dissolution/recrystallization process results in the decrease of porosity, leading to an increase in the observed intensity of these peaks. This hypothesis was supported by the SEM analysis, where the substrate grains (porosity) seem to merge during printing.

The total content of both vitamins was released within $10 \mathrm{~min}$. Fitting of the obtained data on two non-linear models revealed the kinetics of the release profiles. Optimal fitting was evidenced on first-order kinetic model for the investigated vitamins-loaded sugar-sheet substrates, with significantly higher $\mathrm{R}^{2}$ values, compared to the Korsmeyer-Peppas model. The first-order kinetic model exhibits the gradual reduction of the release rate over time, and has been reported to represent the release behavior of water soluble APIs from porous matrices [58]. Regarding the in vitro permeation studies, variations in the composition of the dosage forms resulted in a significant increase of the cumulative amounts of the vitamins that permeated the cellulosic membrane. Increased amounts of vitamins also showed an increasing value for $\mathrm{J}_{\mathrm{ss}}$ and for $\mathrm{P}_{\mathrm{app}}(p<0.05)$. This was attributed to the development of concentration gradients between the donor and the acceptor chambers, relevant to the increase in loading of the vitamins [50].

\section{Materials and Methods}

\subsection{Materials}

Thiamine Hydrochloride and Nicotinic acid were purchased from Fagron Hellas (Trikala, Greece). Propylene glycol (>99.5\%) (PG) was purchased from Sigma-Aldrich (Steinheim, Germany). Décor Paper Plus edible sugar sheets (A4 dimension) were purchased from Kopyform GmbH (Beindersheim, Germany). The carbohydrate compounds of the substrates are sucrose, maltodextrin and dextrose. 
Further information on the composition of this product can be found in the manufacturer's website (www.kopyform.com). All other compounds used in the current study were of analytical grade.

\subsection{High Performance Liquid Chromatography (HPLC)}

The quantification of the vitamins was accomplished via an HPLC system, which consisted of two LC-20AD pumps, a SIL-10AD autosampler (injection volume $100 \mu \mathrm{L}$ ), and a UV-DAD detector, with a Shimadzu LC Solution data system (Shimadzu, Kyoto, Japan). The wavelength chosen for the detection of both vitamins was $205 \mathrm{~nm}$. The stationary phase was a Spherisorb ${ }^{\circledR} \mathrm{CN}-\mathrm{RP}$ column (25 $\mathrm{cm}, 4.6 \mathrm{~mm}$ ) with $5 \mu \mathrm{m}$ particle size. The temperature of the samples during the analysis was set at 20 ${ }^{\circ} \mathrm{C}$ while the column temperature was $25^{\circ} \mathrm{C}$. A mixture consisting of $20 \mathrm{mmol} / \mathrm{L}$ sodium dihydrogen phosphate solution adjusted to $\mathrm{pH} 3.0$ with $85 \% \mathrm{H}_{3} \mathrm{PO}_{4}$ (aq) and Acetonitrile was used as mobile phase. The separation of the two vitamins was performed in gradient mode. Two different gradient run conditions were programmed for the in vitro release and permeation study as described in Tables 6 and 7. The retention times for $\mathrm{NA}$ and $\mathrm{THCl}$ in $\mathrm{SS}$ was $6.6 \mathrm{~min}$ and $13.4 \mathrm{~min}$, respectively, whereas the retention times in PBS was $7 \mathrm{~min}$ and $11.7 \mathrm{~min}$ for the release and permeation studies, respectively. The HPLC analytical method was validated according to ICH [59] guidelines in terms of linearity, selectivity (blank and spiked sample), limit of detection (LOD), limit of quantitation (LOQ), precision, and accuracy (Table 8). Stock standard solutions of both vitamins were prepared in methanol and thereafter appropriate dilutions using SS pH 6.8 and $\mathrm{PBS}$ pH 7.4 as diluent were performed.

Table 6. Gradient conditions for the elution of $\mathrm{THCl}$ and NA in simulated saliva (SS).

\begin{tabular}{cccc}
\hline Time (min) & ACN (\%) & Phosphate Buffer (\%) & Flow Rate (mL/min) \\
\hline $0-6$ & 2 & 98 & 0.5 \\
$6-8$ & 5 & 95 & 0.5 \\
$8-13$ & 15 & 85 & 1.0 \\
$13-15$ & 25 & 75 & 1.0 \\
$15-18$ & 2 & 98 & 0.5 \\
\hline
\end{tabular}

Table 7. Gradient conditions for the elution of $\mathrm{THCl}$ and NA in PBS.

\begin{tabular}{cccc}
\hline Time (min) & ACN (\%) & Phosphate Buffer (\%) & Flow Rate (mL/min) \\
\hline $0-6$ & 2 & 98 & 0.5 \\
$6-7$ & 5 & 95 & 0.5 \\
$7-11$ & 10 & 90 & 0.5 \\
$11-15$ & 2 & 98 & 0.5 \\
\hline
\end{tabular}

Table 8. Data analysis of validation tests.

\begin{tabular}{cccc}
\hline & & Release Tests & Permeation Tests \\
\hline & Concentration range & $0.596-19.2 \mu \mathrm{g} / \mathrm{mL}$ & $0.632-24.96 \mu \mathrm{gg} / \mathrm{ml}$ \\
Calibration curve & $\mathrm{y}=785579.7 \mathrm{x}-257656$ & $\mathrm{y}=604067.2 \mathrm{x}-206475.1$ \\
$\mathrm{R}^{2}$ & 0.9999 & 0.9999 \\
$\mathrm{NA}$ & 0.196 & 0.086 \\
& Limit of detection (LOD) & 0.595 & 0.261 \\
& Limit of quantitation (LOQ) & $>95.6 \%$ & $>96.1$ \\
Mean \%Recovery & 3.1 & 2.01 \\
\hline Mean \%RSD & $1.184-20.16 \mu \mathrm{g} / \mathrm{ml}$ & $1.232-184.8 \mu \mathrm{g} / \mathrm{ml}$ \\
$\mathrm{THCl}$ & $282969.4 \mathrm{x}-6572$ & $260781.98 \mathrm{x}-49662$ \\
& Concentration range & 0.9992 & 0.9996 \\
& Calibration curve & 0.336 & 0.591 \\
$\mathrm{R}^{2}$ & 1.017 & 1.789 \\
& LOD & $>97.3$ & $>98.4$ \\
& LOQ & 3.7 & 2.51 \\
\hline
\end{tabular}




\subsection{Solubility Studies}

The solubility studies for each vitamin were conducted in distilled water as the main solvent, and in PG as surface tension and viscosity modifier. Airtight glass vials, containing $10 \mathrm{~mL}$ of each solvent, were placed under magnetic stirring $(200 \mathrm{rpm})$. Pre-weighed amounts of $\mathrm{THCl}$ and NA were gradually added in the solvents, until a cloudy mixture was produced, suggesting that saturation solubility has been achieved. After $24 \mathrm{~h}, 5 \mathrm{~mL}$ of each mixture were sampled, centrifuged at $4000 \mathrm{rcf}$ for $30 \mathrm{~min}$, and filtered through $0.45 \mu \mathrm{m}$ Whatman Nylon filters (Whatman International Ltd., Maidstone, UK). The supernatants were collected and the saturation solubility of $\mathrm{THCl}$ and $\mathrm{NA}$ in each solvent was quantified by HPLC.

\subsection{Ink Development}

The two solvents were mixed under different ratios, to produce a vitamin-loaded ink with appropriate rheological behavior. A Micro Ostwald viscometer (SI Analytics GmbH, Mainz, Germany) was used to determine the kinematic viscosity $(v)$ of three different vitamin-free solvent ratios, in triplicate. The dynamic viscosity (n) was calculated from the equation $n=v \times p$. The density $(p)$ of each sample was determined gravimetrically. The addition of vitamins in the ink formulation can alter the rheological behavior of the ink samples, so additional rheological measurements were conducted after the vitamin loading. The surface tension of the optimal samples was determined by a CAM 200 contact angle goniometer (KSV Instruments, Helsinki, Finland), and the data analysis was performed with the aid of One Attension software (Biolin Scientific, Espoo, Finland).

\subsection{Printing of Buccal Films}

The buccal films were prepared using a Canon MG2950 (Canon Greece, Athens, Greece). The cartridge with the black ink was cleaned and filled with the vitamin solution. Word 2010 (Microsoft Inc., Redmond, DC, USA) was used to generate square patterns of $2 \mathrm{~cm} \times 2 \mathrm{~cm}$ onto the sugar sheet substrate. In order to increase the amount of the vitamins onto the substrate, the printing process was performed with one, five or nine sequential passes. After the printing process, the films were isolated manually from the substrate by using a surgical blade.

\subsection{Vitamins Loading and Water Uptake}

The produced films were dispersed in $50 \mathrm{~mL}$ distilled water and kept in sealed glass vials for 4 $\mathrm{h}$ under magnetic stirring ( $300 \mathrm{rpm}) .5 \mathrm{~mL}$ of each vial was withdrawn and centrifuged at $4000 \mathrm{rcf}$ for $20 \mathrm{~min}$. The supernatant was collected and analyzed by HPLC, to determine the amount of the vitamins on each film. To evaluate the water absorption capacity, printed films were immersed in Petri dishes, containing $1 \mathrm{~mL}$ of simulated saliva (SS) pH 6.8 ( $0.8 \%$ sodium chloride, $0.019 \%$ potassium phosphate-monobasic and $0.238 \%$ sodium phosphate-dibasic $(w / v))$ [60]. At regular time intervals, the films were removed from the Petri dishes, whipped out carefully to remove excess water and weighed. The water uptake $(\mathrm{WU})$ was estimated as $\% W U=((w 2-w 1) \times 100) / w 1))$, where $w 1$ and $w 2$ is the weight of each film before and after immersion in the SS medium.

\subsection{Thickness and Moisture Content}

The thickness of the three formulations and the plain sugar sheet was determined by a 0-25 $\mathrm{mm}$ $( \pm 0.01 \mathrm{~mm})$ handheld caliper (Standard Gage, Hexagon Metrology, Stockholm, Sweden). Five random areas of each film were measured to obtain the average value $(n=3)$. The moisture content was calculated with the drying method. Sugar sheet, 1-, 5-, and 9-printed films were accurately weighed before and after drying at $105^{\circ} \mathrm{C}$ for $4 \mathrm{~h}(n=6)$. The mass loss observed after $4 \mathrm{~h}$ of drying was attributed to water evaporation of each film. To ensure the absence of simultaneous thermal decomposition phenomena at this temperature, thermo-gravimetric analysis (Shimadzu TGA-50 instrument, Tokyo, 
Japan) was performed. The samples ( $3 \mathrm{mg}$ ) were placed in aluminum pans and were heated in the 30-300 ${ }^{\circ} \mathrm{C}$ range, with a heating rate of $10^{\circ} \mathrm{C} /$ min under nitrogen environment.

\subsection{Physiochemical Characterization}

The morphological characteristics of the printed films were evaluated by scanning electron microscopy (SEM), using a Zeiss SUPRA 35VP microscope (Zeiss, Oberkochen, Germany). Thermal analysis of the printed formulations was carried out by differential scanning calorimetry (DSC). The thermograms of the films and the raw materials were recorded by a DSC 204 F1 Phoenix (Netzsch, Selb, Germany) instrument. Samples, weighing approximately $5 \mathrm{mg}$, were placed in aluminum pans and were heated at a rate of $10{ }^{\circ} \mathrm{C} / \mathrm{min}$, between $30-330{ }^{\circ} \mathrm{C}$. Fourier Transform Infrared Spectroscopy (FTIR) studies were also conducted by an IRPrestige-21 (Shimadzu, Kyoto, Japan) instrument. The spectrum of each sample was recorded in the range $650-4000 \mathrm{~cm}^{-1}$, with $2 \mathrm{~cm}^{-1}$ resolution.

\subsection{FTIR Data Analysis}

\subsubsection{Two-Dimensional Fourier Transformation Infrared Correlation Spectroscopy (2D-COS-FTIR)}

2DCorrFTIR was applied to monitor the dynamic spectral changes of the films' surface during subsequent passes through the printer device. Specimens printed 1 to 14 times were prepared and the data were analyzed using 2D Shige (2DShige $\subset$, Shigeaki Morita, Kwansei-Gakuin University, 2004-2005) [61,62].

\subsubsection{Moving-Window 2D Correlation (MW2D) Spectroscopy}

MW2D technique was applied to monitor the induced spectral variations on the drug loaded specimens, during sequential passes through the printer. The spectral data were analyzed using $2 \mathrm{D}$ Shige package, through the generation of a 2D map spread of the spectral variables as a function of the external perturbation (1-14 printing passes) [63].

\subsection{In Vitro Studies}

\subsubsection{Thiamine Hydrochloride and Nicotinic Acid Release in Simulated Saliva}

The in vitro release studies were conducted in SS, in triplicate. The printed formulations of different doses were enclosed in metal grids and submerged in double-walled glass vessels containing $50 \mathrm{~mL}$ of SS. The vessels containing the films were kept under gentle agitation $(100 \mathrm{rpm})$ at $37^{\circ} \mathrm{C} .1$ $\mathrm{mL}$ from each vessel was withdrawn at pre-determined time points, centrifuged at $4000 \mathrm{rcf}$ for 20 min, filtered through a $0.45 \mu \mathrm{m}$ filter and analyzed by HPLC. Two kinetic models were fitted on the release data (first order, Korsmeyer-Peppas), using the software SigmaPlot v.12.5 (Systat Software, Inc., Chicago, IL, USA) and a curve fit library (release.jfl).

\subsubsection{Permeation Studies}

The in vitro permeation of the two vitamins across a cellulosic membrane (Dialysis Tubing, MW cut-off, Sigma-Aldrich, Steinheim, Germany) was studied in Franz vertical diffusion cells (diffusion area $4.9 \mathrm{~cm}^{2}$, compartment volume $20 \mathrm{~mL}$ ). In order for the films to fit properly into the donor compartment, round films $(\mathrm{r}=1.128 \mathrm{~cm})$ with a surface area of approximately $4 \mathrm{~cm}^{2}$ were printed. The acceptor and the donor chambers were filled with degassed PBS pH 7.4 and SS pH 6.8, respectively, and maintained under constant magnetic stirring $(110 \mathrm{rpm})$ at $37^{\circ} \mathrm{C}$, whereas the cellulose membrane was properly mounted between the two compartments. Samples of $1 \mathrm{~mL}$ were withdrawn from the acceptor compartment at predetermined time intervals, centrifuged at $4000 \mathrm{rcf}$ for $20 \mathrm{~min}$, filtered through a $0.45 \mathrm{~m}$ filter, and analyzed by HPLC. The amount of the vitamins permeated through the membrane was plotted against time, and the slope of the linear section of the curve determined the 
steady-state flux $\left(\mathrm{J}_{\mathrm{ss}}\right)$. The apparent permeability coefficient $\left(\mathrm{P}_{\mathrm{app}}\right)$ was calculated as $\mathrm{P}_{\mathrm{app}}=\mathrm{J}_{\mathrm{ss}} / \mathrm{C}_{\mathrm{d}}$, where $\mathrm{C}_{\mathrm{d}}$ indicates the concentration of $\mathrm{THCl}$ and $\mathrm{NA}$ in the donor compartment.

\subsection{Statistical Analysis}

The data are presented as the mean $\pm \mathrm{SD}$. The significance level is set at $p<0.05$ (Student's $t$-test).

\section{Conclusions}

Buccal films of B-complex vitamins were developed via 2D printing technology, a new and safe way for producing drug or vitamin loaded formulations. The solubility studies revealed that the vitamins are very soluble in distilled water and PG, two non-toxic and low-cost solvents. The increased solubility suggests that the doses could be easily adjusted to specific needs, regarding the amount of vitamins dissolved in the ink formulation and the number of sequential printing passes. The physicochemical characterization of the printed films presented the morphology of the formulations and revealed the amorphous state of the vitamins. The release profiles indicated the rapid release from the matrix, whereas the permeation profiles showed that increasing the number of sequential passes improved the permeability of each vitamin.

Author Contributions: Conceptualization, G.E. and D.F.; Formal analysis, P.K.M.; Investigation, G.E., P.K.M., E.M., N.M., E.A., and N.B.; Methodology, G.E. and D.F.; Validation, C.M.; Writing-original draft, P.K.M. and G.E.; Writing-review and editing, G.E., E.A., C.M., N.B. and D.F. All authors have read and agreed to the published version of the manuscript.

Funding: This research received no external funding.

Conflicts of Interest: The authors declare no conflict of interest.

\section{References}

1. Thabet, Y.; Sibanc, R.; Breitkreutz, J. Printing pharmaceuticals by inkjet technology: Proof of concept for stand-alone and continuous in-line printing on orodispersible films. J. Manuf. Process. 2018, 35, $205-215$. [CrossRef]

2. Kollamaram, G.; Hopkins, S.C.; Glowacki, B.A.; Croker, D.M.; Walker, G.M. Inkjet printing of paracetamol and indomethacin using electromagnetic technology: Rheological compatibility and polymorphic selectivity. Eur. J. Pharm. Sci. 2018, 115, 248-257. [CrossRef] [PubMed]

3. Magdassi, S. The Chemistry of Inkjet Inks; World Scientific Publishing Co.: Singapore, 2010; ISBN 978-981-281-821-8.

4. Tian, Y.; Orlu, M.; Woerdenbag, H.J.; Scarpa, M.; Kiefer, O.; Kottke, D.; Sjöholm, E.; Öblom, H.; Sandler, N.; Hinrichs, W.L.J.; et al. Oromucosal films: From patient centricity to production by printing techniques. Expert Opin. Drug Deliv. 2019, 16, 981-993. [CrossRef]

5. Preis, M.; Breitkreutz, J.; Sandler, N. Perspective: Concepts of printing technologies for oral film formulations. Int. J. Pharm. 2015, 494, 578-584. [CrossRef]

6. Kolakovic, R.; Viitala, T.; Ihalainen, P.; Genina, N.; Peltonen, J.; Sandler, N. Printing technologies in fabrication of drug delivery systems. Expert Opin. Drug Deliv. 2013, 10, 1711-1723. [CrossRef] [PubMed]

7. Eleftheriadis, G.K.; Katsiotis, C.S.; Genina, N.; Boetker, J.; Rantanen, J.; Fatouros, D.G. Manufacturing of hybrid drug delivery systems by utilizing the fused filament fabrication (FFF) technology. Expert Opin. Drug Deliv. 2020, 17, 1-5. [CrossRef]

8. $\quad$ Eleftheriadis, G.K.; Monou, P.K.; Bouropoulos, N.; Boetker, J.; Rantanen, J.; Jacobsen, J.; Vizirianakis, I.S.; Fatouros, D.G. Fabrication of Mucoadhesive Buccal Films for Local Administration of Ketoprofen and Lidocaine Hydrochloride by Combining Fused Deposition Modeling and Inkjet Printing. J. Pharm. Sci. 2020. [CrossRef]

9. Eleftheriadis, G.K.; Katsiotis, C.S.; Andreadis, D.A.; Tzetzis, D.; Ritzoulis, C.; Bouropoulos, N.; Kanellopoulou, D.; Andriotis, E.G.; Tsibouklis, J.; Fatouros, D.G. Inkjet printing of a thermolabile model drug onto FDM-printed substrates: Formulation and evaluation. Drug Dev. Ind. Pharm. 2020, 46, 1253-1264. [CrossRef] 
10. Daly, R.; Harrington, T.S.; Martin, G.D.; Hutchings, I.M. Inkjet printing for pharmaceutics-A review of research and manufacturing. Int. J. Pharm. 2015, 494, 554-567. [CrossRef]

11. Varan, C.; Wickström, H.; Sandler, N.; Aktaş, Y.; Bilensoy, E. Inkjet printing of antiviral PCL nanoparticles and anticancer cyclodextrin inclusion complexes on bioadhesive film for cervical administration. Int. J. Pharm. 2017, 531, 701-713. [CrossRef]

12. Meléndez, P.A.; Kane, K.M.; Ashvar, C.S.; Albrecht, M.; Smith, P.A. Thermal Inkjet Application in the Preparation of Oral Dosage Forms: Dispensing of Prednisolone Solutions and Polymorphic Characterization by Solid-State Spectroscopic Techniques. J. Pharm. Sci. 2008, 97, 2619-2636. [CrossRef] [PubMed]

13. Pardeike, J.; Strohmeier, D.M.; Schrödl, N.; Voura, C.; Gruber, M.; Khinast, J.G.; Zimmer, A. Nanosuspensions as advanced printing ink for accurate dosing of poorly soluble drugs in personalized medicines. Int. J. Pharm. 2011, 420, 93-100. [CrossRef] [PubMed]

14. Genina, N.; Fors, D.; Palo, M.; Peltonen, J.; Sandler, N. Behavior of printable formulations of loperamide and caffeine on different substrates_Effect of print density in inkjet printing. Int. J. Pharm. 2013, 453, 488-497. [CrossRef] [PubMed]

15. Genina, N.; Janßen, E.M.; Breitenbach, A.; Breitkreutz, J.; Sandler, N. Evaluation of different substrates for inkjet printing of rasagiline mesylate. Eur. J. Pharm. Biopharm. 2013, 85, 1075-1083. [CrossRef] [PubMed]

16. Sandler, N.; Määttänen, A.; Ihalainen, P.; Kronberg, L.; Meierjohann, A.; Viitala, T.; Peltonen, J. Inkjet printing of drug substances and use of porous substrates-towards individualized dosing. J. Pharm. Sci. 2011, 100, 3386-3395. [CrossRef]

17. Wickström, H.; Broos, A.; Nyman, J.O.; Kortesmäki, E.; Eklund, P.; De Beer, T.; Preis, M.; Sandler, N. Handheld colorimeter as quality control tool for inkjet printed flexible levothyroxine doses for pediatric use. Int. J. Pharm. 2018, 536, 508-509. [CrossRef]

18. Edinger, M.; Bar-Shalom, D.; Sandler, N.; Rantanen, J.; Genina, N. QR encoded smart oral dosage forms by inkjet printing. Int. J. Pharm. 2018, 536, 138-145. [CrossRef]

19. Trenfield, S.J.; Xian Tan, H.; Awad, A.; Buanz, A.; Gaisford, S.; Basit, A.W.; Goyanes, A. Track-and-trace: Novel anti-counterfeit measures for 3D printed personalized drug products using smart material inks. Int. J. Pharm. 2019, 567, 118443. [CrossRef]

20. Batista, P.; Castro, P.; Madureira, A.R.; Sarmento, B.; Pintado, M. Development and Characterization of Chitosan Microparticles-in-Films for Buccal Delivery of Bioactive Peptides. Pharmaceuticals 2019, 12, 32. [CrossRef]

21. Lam, J.K.W.; Xu, Y.; Worsley, A.; Wong, I.C.K. Oral transmucosal drug delivery for pediatric use. Adv. Drug Deliv. Rev. 2014, 73, 50-62. [CrossRef]

22. Garipova, V.R.; Gennari, C.G.M.; Selmin, F.; Cilurzo, F.; Moustafine, R.I. Mucoadhesive Interpolyelectrolyte Complexes for the Buccal Delivery of Clobetasol. Polymers 2018, 10, 85. [CrossRef]

23. Khan, S.; Boateng, J. Effects of Cyclodextrins ( $\beta$ and $\gamma$ ) and l-Arginine on Stability and Functional Properties of Mucoadhesive Buccal Films Loaded with Omeprazole for Pediatric Patients. Polymers 2018, 10, 157. [CrossRef] [PubMed]

24. Ruiz-Rubio, L.; Alonso, M.L.; Pérez-Álvarez, L.; Alonso, R.M.; Vilas, J.L.; Khutoryanskiy, V.V. Formulation of Carbopol ${ }^{\circledR} /$ Poly(2-ethyl-2-oxazoline)s Mucoadhesive Tablets for Buccal Delivery of Hydrocortisone. Polymers 2018, 10, 175. [CrossRef] [PubMed]

25. Eleftheriadis, G.K.; Ritzoulis, C.; Bouropoulos, N.; Tzetzis, D.; Andreadis, D.A.; Boetker, J.; Rantanen, J.; Fatouros, D.G. Unidirectional drug release from 3D printed mucoadhesive buccal films using FDM technology: In vitro and ex vivo evaluation. Eur. J. Pharm. Biopharm. 2019, 144, 180-192. [CrossRef] [PubMed]

26. Junior, B.R.A.; Soares, F.L.F.; Ardila, J.A.; Durango, L.G.C.; Forim, M.R.; Carneiro, R.L. Determination of B-complex vitamins in pharmaceutical formulations by surface-enhanced Raman spectroscopy. Spectrochim. Acta A Mol. Biomol. Spectrosc. 2018, 188, 589-595. [CrossRef] [PubMed]

27. Abd El Azim, H.; Nafee, N.; Ramadan, A.; Khalafallah, N. Liposomal buccal mucoadhesive film for improved delivery and permeation of water-soluble vitamins. Int. J. Pharm. 2015, 488, 78-85. [CrossRef] [PubMed]

28. Mohamad, S.A.; Sarhan, H.A.; Abdelkader, H.; Mansour, H.F. Vitamin B12-Loaded Buccoadhesive Films as a Noninvasive Supplement in Vitamin B12 Deficiency: In vitro Evaluation and in vivo Comparative Study with Intramuscular Injection. J. Pharm. Sci. 2017, 106, 1849-1858. [CrossRef] 
29. Fonseca-Santos, B.; Chorilli, M. An overview of polymeric dosage forms in buccal drug delivery: State of art, design of formulations and their in vivo performance evaluation. Mater. Sci. Eng. C 2018, 86, 129-143. [CrossRef]

30. Juveriya Fathima, S.; Fathima, I.; Abhishek, V.; Khanum, F. Phosphatidylcholine, an edible carrier for nanoencapsulation of unstable thiamine. Food Chem. 2016, 197, 562-570. [CrossRef]

31. Alizadeh, T.; Akhoundian, M.; Ganjali, M.R. An innovative method for synthesis of imprinted polymer nanomaterial holding thiamine (vitamin B1) selective sites and its application for thiamine determination in food samples. J. Chromatogr. B 2018, 1084, 166-174. [CrossRef]

32. Shils, M.E.; Shike, M. Modern Nutrition in Health and Disease; Lippincott Williams \& Wilkins: Philadelphia, PA, USA, 2006; ISBN 978-0-7817-4133-0.

33. Lebiedzińska, A.; Szefer, P. Vitamins B in grain and cereal-Grain food, soy-products and seeds. Food Chem. 2006, 95, 116-122. [CrossRef]

34. Sun, W.-P.; Zhai, M.-Z.; Li, D.; Zhou, Y.; Chen, N.-N.; Guo, M.; Zhou, S.-S. Comparison of the effects of nicotinic acid and nicotinamide degradation on plasma betaine and choline levels. Clin. Nutr. 2017, 36, 1136-1142. [CrossRef] [PubMed]

35. Panyoyai, N.; Bannikova, A.; Small, D.M.; Shanks, R.A.; Kasapis, S. Diffusion of nicotinic acid in spray-dried capsules of whey protein isolate. Food Hydrocoll. 2016, 52, 811-819. [CrossRef]

36. Sun, Y.; Zhang, Y.; Li, Y.; Cheng, J.; Chen, S.; Xiao, Y.; Ao, G. Synthesis and biological evaluation of novel hydrogen sulfide releasing nicotinic acid derivatives. Bioorg. Med. Chem. 2016, 24, 5368-5373. [CrossRef]

37. Buckel, L.; Kremer, J.I.; Stegmüller, S.; Richling, E. Fast, Sensitive and Robust Determination of Nicotinic Acid (Vitamin B3) Contents in Coffee Beverages Depending on the Degree of Roasting and Brewing Technique. Proceedings 2019, 11, 1013. [CrossRef]

38. Naik, S.R.; Rupawalla, E.N.; Sheth, U.K. Anti-inflammatory activity of thiamine and nicotinic acid. Biochem. Pharmacol. 1970, 19, 2867-2873. [CrossRef]

39. Smart, J.D. The basics and underlying mechanisms of mucoadhesion. Adv. Drug Deliv. Rev. 2005, 57, 1556-1568. [CrossRef]

40. Smart, J.D. Drug delivery using buccal-adhesive systems. Adv. Drug Deliv. Rev. 1993, 11, 253-270. [CrossRef]

41. Cook, S.L.; Woods, S.; Methven, L.; Parker, J.K.; Khutoryanskiy, V.V. Mucoadhesive polysaccharides modulate sodium retention, release and taste perception. Food Chem. 2018, 240, 482-489. [CrossRef]

42. Silva Favacho, H.A.; Oliveira do Couto, R.; Ferreira Duarte, M.P.; Garofo Peixoto, M.P.; Vianna Lopez, R.F.; Pedrazzi, V.; Masetto de Gaitani, C.; De Freitas, O. Synergy between surfactants and mucoadhesive polymers enhances the transbuccal permeation of local anesthetics from freeze-dried tablets. Mater. Sci. Eng. C 2020, 108, 110373. [CrossRef]

43. Eshak, E.S.; Arafa, A.E. Thiamine deficiency and cardiovascular disorders. Nutr. Metab. Cardiovasc. Dis. 2018, 28, 965-972. [CrossRef] [PubMed]

44. Smithline, H.A.; Donnino, M.; Greenblatt, D.J. Pharmacokinetics of high-dose oral thiamine hydrochloride in healthy subjects. BMC Clin. Pharmacol. 2012, 12, 4. [CrossRef] [PubMed]

45. Neuvonen, P.J.; Roivas, L.; Laine, K.; Sundholm, O. The bioavailability of sustained release nicotinic acid formulations. Br. J. Clin. Pharmacol. 1991, 32, 473-476. [CrossRef] [PubMed]

46. MacKay, D.; Hathcock, J.; Guarneri, E. Niacin: Chemical forms, bioavailability, and health effects. Nutr. Rev. 2012, 70, 357-366. [CrossRef]

47. Rader, J.I.; Calvert, R.J.; Hathcock, J.N. Hepatic toxicity of unmodified and time-release preparations of niacin. Am. J. Med. 1992, 92, 77-81. [CrossRef]

48. Gilhotra, R.M.; Ikram, M.; Srivastava, S.; Gilhotra, N. A clinical perspective on mucoadhesive buccal drug delivery systems. J. Biomed. Res. 2014, 28, 81-97. [CrossRef]

49. Buanz, A.B.M.; Saunders, M.H.; Basit, A.W.; Gaisford, S. Preparation of Personalized-dose Salbutamol Sulphate Oral Films with Thermal Ink-Jet Printing. Pharm. Res. 2011, 28, 2386. [CrossRef]

50. Eleftheriadis, G.K.; Monou, P.K.; Bouropoulos, N.; Fatouros, D.G. In Vitro Evaluation of 2D-Printed Edible Films for the Buccal Delivery of Diclofenac Sodium. Materials 2018, 11, 864. [CrossRef]

51. Menon, D.; Dollimore, D.; Alexander, K.S. A TG-DTA study of the sublimation of nicotinic acid. Thermochim. Acta 2002, 392, 237-241. [CrossRef] 
52. Arioglu-Tuncil, S.; Bhardwaj, V.; Taylor, L.S.; Mauer, L.J. Amorphization of thiamine chloride hydrochloride: A study of the crystallization inhibitor properties of different polymers in thiamine chloride hydrochloride amorphous solid dispersions. Food Res. Int. 2017, 99, 363-374. [CrossRef]

53. Al-Rashood, K.A.M.; Al-Shammary, F.J.; Mian, N.A.A. Analytical Profile of Thiamine Hydrochloride. In Analytical Profiles of Drug Substances; Elsevier: New York, NY, USA, 1990; Volume 18, pp. 413-458. ISBN 978-0-12-260818-6.

54. Anirudhan, T.S.; Divya, P.L.; Nima, J. Silylated montmorillonite based molecularly imprinted polymer for the selective binding and controlled release of thiamine hydrochloride. React. Funct. Polym. 2013, 73, 1144-1155. [CrossRef]

55. Karbasi, M.; Askari, G.; Madadlou, A. Surface decoration of whey protein microgels through the Maillard conjugation with maltodextrin. Food Hydrocoll. 2019, 91, 190-197. [CrossRef]

56. Koczoń, P.; Dobrowolski, J.C.; Lewandowski, W.; Mazurek, A.P. Experimental and theoretical IR and Raman spectra of picolinic, nicotinic and isonicotinic acids. J. Mol. Struct. 2003, 655, 89-95. [CrossRef]

57. Zhang, L.; Zeng, X.; Fu, N.; Tang, X.; Sun, Y.; Lin, L. Maltodextrin: A consummate carrier for spray-drying of xylooligosaccharides. Food Res. Int. 2018, 106, 383-393. [CrossRef] [PubMed]

58. Costa, P.; Sousa Lobo, J.M. Modeling and comparison of dissolution profiles. Eur. J. Pharm. Sci. 2001, 13, 123-133. [CrossRef]

59. ICH Q2 (R1) Validation of Analytical Procedures: Text and Methodology. Available online: https://www. ema.europa.eu/en/ich-q2-r1-validation-analytical-procedures-text-methodology (accessed on 26 June 2020).

60. Marques, M.; Löbenberg, R.; Almukainzi, M. Simulated Biological Fluids with Possible Application in Dissolution Testing. Dissolution Technol. 2011, 18, 15-28. [CrossRef]

61. Noda, I.; Ozaki, Y. Two-Dimensional Correlation Spectroscopy-Applications in Vibrational and Optical Spectroscopy, 1st ed.; John Wiley \& Sons Ltd.: Chichester, UK, 2004.

62. Noda, I. Techniques of two-dimensional (2D) correlation spectroscopy useful in life science research. Biomed. Spectrosc. Imaging 2015, 4, 109-127. [CrossRef]

63. Morita, S.; Shinzawa, H.; Noda, I.; Ozaki, Y. Perturbation-correlation moving-window two-dimensional correlation spectroscopy. Appl. Spectrosc. 2006, 60, 398-406. [CrossRef]

(C) 2020 by the authors. Licensee MDPI, Basel, Switzerland. This article is an open access article distributed under the terms and conditions of the Creative Commons Attribution (CC BY) license (http://creativecommons.org/licenses/by/4.0/). 